\title{
Quantification of Bone Metastasis of Castration-resistant Prostate Cancer After Enzalutamide and Abiraterone Acetate Using Bone Scan Index on Bone Scintigraphy
}

\author{
SUGURU KADOMOTO ${ }^{1}$, HIROSHI YAEGASHI ${ }^{1}$, KAZUFUMI NAKASHIMA $^{1}$, \\ MASASHI IIJIMA ${ }^{1}$, SHOHEI KAWAGUCHI ${ }^{1}$, TAKAHIRO NOHARA ${ }^{1}$, KAZUYOSHI SHIGEHARA ${ }^{1}$, \\ KOUJI IZUMI ${ }^{1}$, YOSHIFUMI KADONO ${ }^{1}$, KENICHI NAKAJIMA ${ }^{2}$ and ATSUSHI MIZOKAMI ${ }^{1}$ \\ ${ }^{I}$ Department of Integrative Cancer Therapy and Urology, \\ Kanazawa University Graduate School of Medical Science, Kanazawa, Japan; \\ ${ }^{2}$ Department of Radiotherapy, Kanazawa University Graduate School of Medical Science, Kanazawa, Japan
}

\begin{abstract}
Background/Aim: This study aimed to evaluate the therapeutic effect of enzalutamide (ENZ) or abiraterone acetate $(A B I)$ on bone metastasis in castration-resistant prostate cancer (CRPC), using bone scan index (BSI). Materials and Methods: Treatment outcomes for 31 patients who had undergone ENZ or ABI treatment were examined for CRPC with bone metastases. Cox proportional-hazards regression models were used to investigate the association between overall survival $(O S)$ and clinical characteristics. Results: Median OS after ENZ or ABI treatment was 29 months. Considering the flare phenomenon, BSI in 17 (55\%) patients decreased following treatment. In multivariate analysis, low baseline BSI value and a decrease in BSI following treatment were associated with longer $O S$ (hazard ratio $[H R]=8.009$; $p=0.35$ and $H R=7.025 ; p=0.045^{*}$, respectively). Conclusion: Low BSI value before ENZ/ABI treatment and a decrease in $B S I$ following ENZ or ABI treatment are independent predictors of longer OS. BSI could be useful for risk assessment of CRPC patients with bone metastases.
\end{abstract}

Androgen deprivation therapy (ADT) is an effective therapy for advanced prostate cancer (PCa) (1), even in cases of $\mathrm{PCa}$ with bone metastasis. Unfortunately, despite responding to

This article is freely accessible online.

Correspondence to: Atsushi Mizokami, MD, Ph.D., Department of Integrative Cancer Therapy and Urology, Kanazawa University Graduate School of Medical Science, 13-1 Takaramachi, Kanazawa, Ishikawa 920-8640, Japan. Tel: +81 762652393, Fax: +81 762344263, e-mail: mizokami@staff.kanazawa-u.ac.jp

Key Words: Bone scan index, castration-resistant prostate cancer, enzalutamide, abiraterone acetate, biomarker. initial ADT, most cases of metastatic PCa eventually become resistant to standard ADT; known as metastatic castrationresistant prostate cancer (CRPC) $(2,3)$. The annual morbidity of PCa in Japan is 120.9 per $1,000,000$ men, respectively, and still on the increase (4).

Although it is often difficult to treat metastatic CRPC (mCRPC) following ADT, docetaxel (DOC) was proven effective against CRPC (5). Subsequently, novel androgen receptor (AR) targeted drugs, including antiandrogen enzalutamide (ENZ) and abiraterone (ABI), have been developed. These drugs extend overall survival (OS) of mCRPC patients both before and after DOC treatment (6-9). Despite treatment effect and progression-free survival (PFS) often being evaluated with prostate-specific antigen (PSA) following ADT and chemotherapy, PSA-PFS is not a good prognostic marker (5). Instead, radiographic evaluation of PFS through computed tomography (CT) or magnetic resonance imaging (MRI), as defined by the modified Response Evaluation Criteria in Solid Tumors (RECIST), is often more suitable (10). Evaluation of bone metastases is not sufficient despite bone metastasis being present in $90 \%$ of mCRPC patients $(2,3)$.

Bone scintigraphy, CT and MRI are commonly used for the diagnosis of bone metastases in $\mathrm{PCa}$; bone scintigraphy is particularly useful for screening of bone metastases. Extent of disease (EOD) scores are often used for evaluation of bone metastasis in PCa (11); although EOD score possesses important prognostic information, it is subjective and lacks quantitative information. Recommendations from the Prostate Cancer Clinical Trials Working Group 3 (PCWG3) are still only semi-quantitative and do not evaluate improvements in bone metastasis following different treatments $(12,13)$.

Recently, a computer-assisted diagnosis system, known as EXINI bone software in Europe and North America (EXINI Diagnostics, Lund, Sweden) and BONENAVI in Japan 
Table I. Clinical characteristics of the 31 study patients.

\begin{tabular}{|c|c|c|c|}
\hline Characteristic & $\mathrm{ABI}(\mathrm{N}=12)$ & ENZ $(\mathrm{N}=19)$ & Total $(\mathrm{N}=31)$ \\
\hline Median age, year (range) & $68(54-76)$ & $70(55-82)$ & $70(54-82)$ \\
\hline \multicolumn{4}{|l|}{ ECOG PS, No } \\
\hline 0 & 5 & 4 & 9 \\
\hline 1 & 7 & 10 & 17 \\
\hline$\leq 2$ & 0 & 5 & 5 \\
\hline Median observation period, months (range) & $19(6-31)$ & $24(3-39)$ & $23(3-39)$ \\
\hline \multicolumn{4}{|l|}{ GS, No } \\
\hline$\geq 9$ & 7 & 12 & 19 \\
\hline 8 & 1 & 4 & 5 \\
\hline$\leq 7$ & 4 & 3 & 7 \\
\hline Post DOC, No & 6 & 9 & 15 \\
\hline Baseline pain, No & 5 & 10 & 15 \\
\hline Median baseline PSA, ng/ml (range) & $23.6(2.3-104.9)$ & $12.9(1.6-8828)$ & $16.5(1.6-8828)$ \\
\hline Median baseline BSI, \% (range) & $0.76(0.09-6.49)$ & $1.819(0-11.69)$ & $1.797(0-11.69)$ \\
\hline BSI flare, No & 2 & 6 & 8 \\
\hline BSI decline, No & 4 & 8 & 12 \\
\hline PSA decline, No & 8 & 14 & 22 \\
\hline
\end{tabular}

(FUJIFILM RI Pharma, Co. Ltd., Tokyo, Japan), has been developed for bone scintigraphy $(14,15)$. This system can be used to calculate bone scan index (BSI), providing objective and quantitative parameters regarding percentage of bone metastases.

The aim of this study was to use BSI to examine changes in bone metastases induced by pre- or post-DOC ENZ or ABI treatment of mCRPC with bone metastases. Utility of BSI evaluation in the treatment of mCRPC patients was retrospectively investigated.

\section{Materials and Methods}

In total, 31 patients were retrospectively assessed, who had been treated with ENZ or ABI, pre- or post-DOC for mCRPC between 2014 and 2017 at the Kanazawa University Hospital. All patients were evaluated by prostate biopsy and bone scintigraphy. All patients were treated initially with combined androgen blockade (CAB) therapy (degarelix, goserelin or leuprorelin and bicalutamide). Following failure of ADT, most patients were treated with anti-androgen drug replacement therapy (using bicalutamide or flutamide). Over $50 \%$ of patients were treated with chlormadinone or ethinylestradiol or estramustine phosphate prior to treatment with DOC or ENZ or ABI. Therapeutic agents were changed upon disease progression or appearance of unacceptable adverse events. Most patients received zoledronic acid or denosumab to treat bone metastasis. None of the patients received cabazitaxel or radium 223 prior to ABI or ENZ. Patient characteristics are listed in Table I. Gleason score (GS) denotes value of biopsy specimen at time of prostate cancer diagnosis. Clinical stages for all patients were evaluated using chest and body CT and bone scintigraphy prior to ENZ or ABI treatment. Patient BSI and PSA values were measured prior to commencement of ENZ or ABI treatment and at 3-month intervals thereafter.
Bone scintigraphy images were obtained in the month preceding induction of ENZ or ABI treatment. Anterior and posterior bone scintigraphy images were analyzed according to a previously described method (15). Individual hotspots were classified as metastatic or non-metastatic using artificial neural networks (ANN); BSI was calculated as percentage of bone metastatic hotspots based on ANN values. BONENAVI version 2 (Fuji film RI Pharma Co. LTD., Tokyo, Japan; Exini Bone, Exini Diagnostics, Lund, Sweden) was used for analysis (16). When surveying patients with metastatic $\mathrm{PCa}$, flare phenomena were considered during treatment of mCRPC.

Cox proportional hazards model with stepwise regression analysis was used to investigate correlation between OS after ENZ or ABI treatment and clinical variables (patient age, Eastern Cooperative Oncology Group (ECOG) performance status (PS), Gleason Score (GS), baseline PSA, previous treatment with DOC, baseline BSI, baseline pain requiring non-steroidal antiinflammatory drugs (NSAIDs) or opioids, BSI flare and decrease of BSI and PSA after ENZ or ABI. Cutoff points for continuous variables were the median values for each variable. Kaplan-Meier curves were used to estimate survival distributions. Differences in survival and BSI change rates were analyzed using log rank tests and Mann-Whitney $U$-tests. Significance level was fixed at $p<0.05$. IBM SPSS Statistics software for Windows, version 22 (IBM Corp, Armonk, NY, USA), was used for all analyses.

\section{Results}

In this study, 24 of 31 (77.4\%) patients presented with only bone metastasis, 4 presented with lymph node and bone metastasis, and 3 presented with lung and bone metastasis, prior to ENZ or ABI treatment. Fourteen of 31 patients (45.2\%) died; $12(38.7 \%)$ due to $\mathrm{PCa}$ and 2 due to pneumonia or drowning.

The median age at the start of treatment with ENZ or ABI was 70 years old (range $=54-82$ years). Median OS after ENZ 

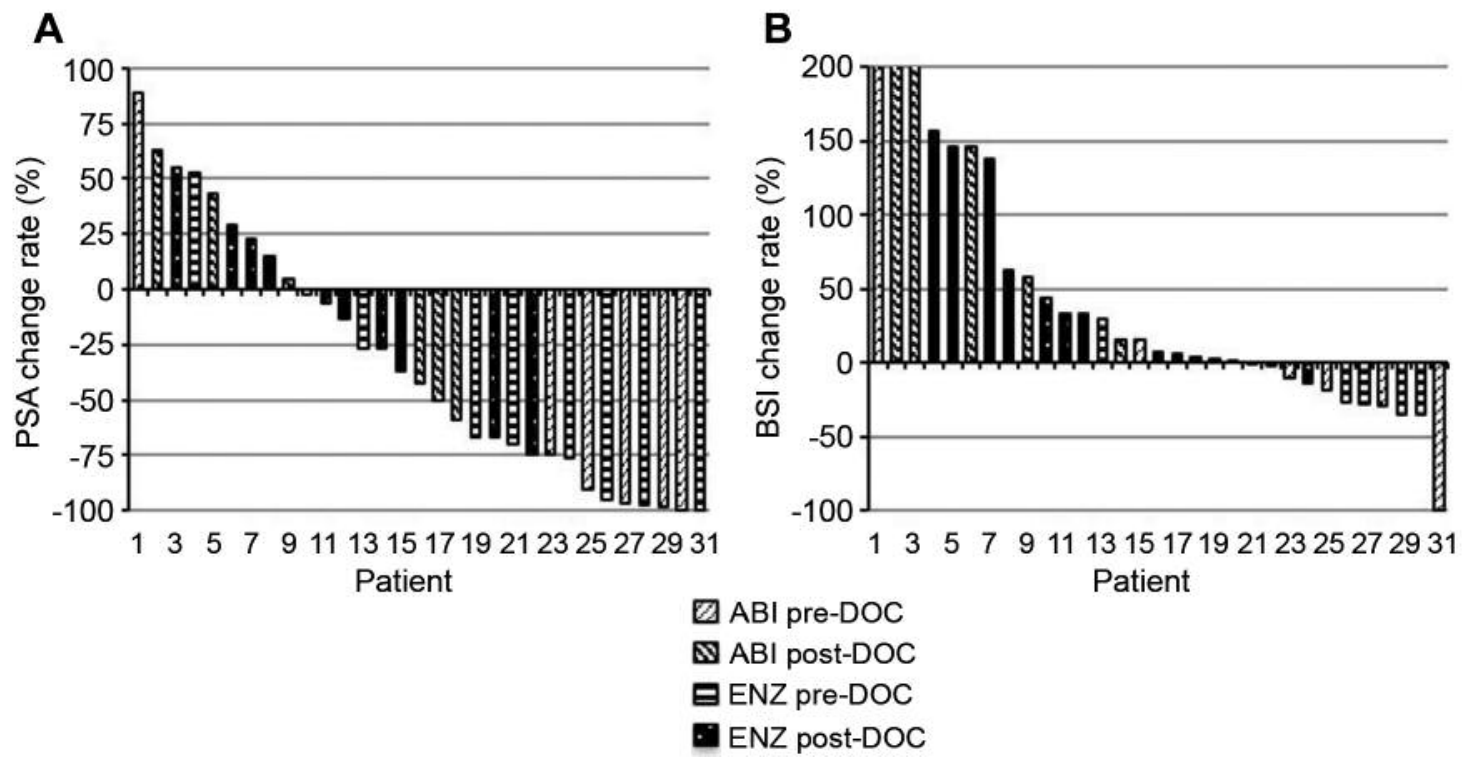

Figure 1. Waterfall plot of maximum change rate and BSI change rate. A. Waterfall plot of maximum PSA change rate. B. Waterfall plot of maximum BSI change rate.

A

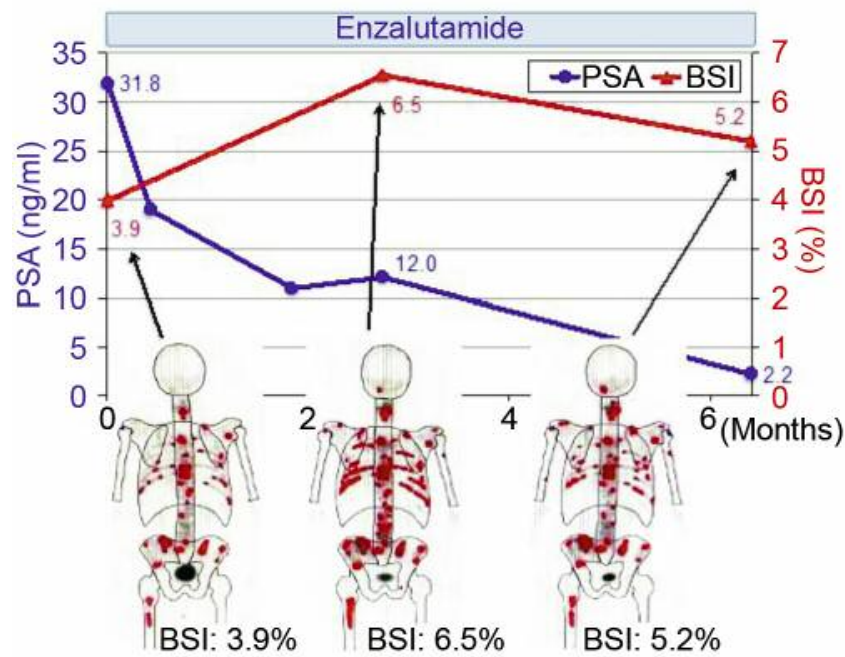

B

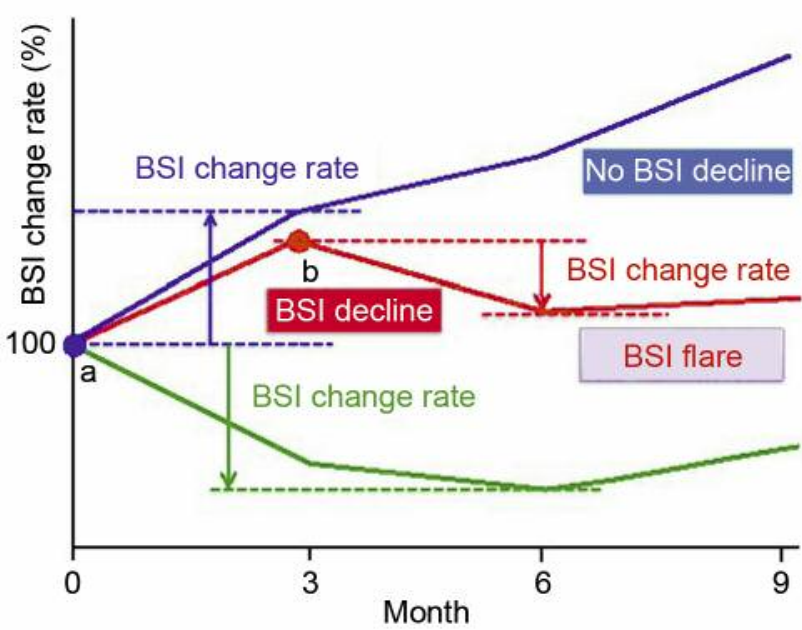

Figure 2. Consideration of BSI flare. A. Images obtained from patient with bone metastatic CRPC. BSI was $3.9 \%$ before ENZ treatment. Bone metastasis is a red triangle. BSI increased 3 months after ENZ treatment (6.5\%) and decreased (5.2\%) 6 months after treatment, although PSA levels decreased from 31.8 to $2.3 \mathrm{ng} / \mathrm{ml}$ during ENZ treatment. B. Reference value for BSI change rate was defined by presence or absence of BSI flare. a: Reference value when BSI flare was not observed during ENZ or ABI treatment. b. Reference value when BSI flare was observed during ENZ or ABI treatment.

or ABI treatment was 29 months (range=3-39 months). Decrease in PSA levels was observed in 22 of 31 patients (71.0\%) (12 cases: pre-DOC, 10 cases: post-DOC). A decrease in PSA of $50 \%$ or more was observed in 15 of the 31 patients ( 5 cases: ABI pre-DOC, 2 cases: ABI post-DOC, 6 cases: ENZ pre-DOC, 2 cases: ENZ post-DOC) (Figure 1A).
Figure $1 \mathrm{~B}$ represents waterfall plots of rate of BSI change from baseline (immediately prior to ENZ or ABI treatment). Of 31 patients, $11(35.5 \%)$ demonstrated a decrease in BSI, including $9(29.0 \%)$ pre-DOC and $2(6.5 \%)$ post-DOC. BSI of one patient decreased by more than $50 \%$ and BSI of 6 (19.4\%) patients decreased by more than $25 \%$. 


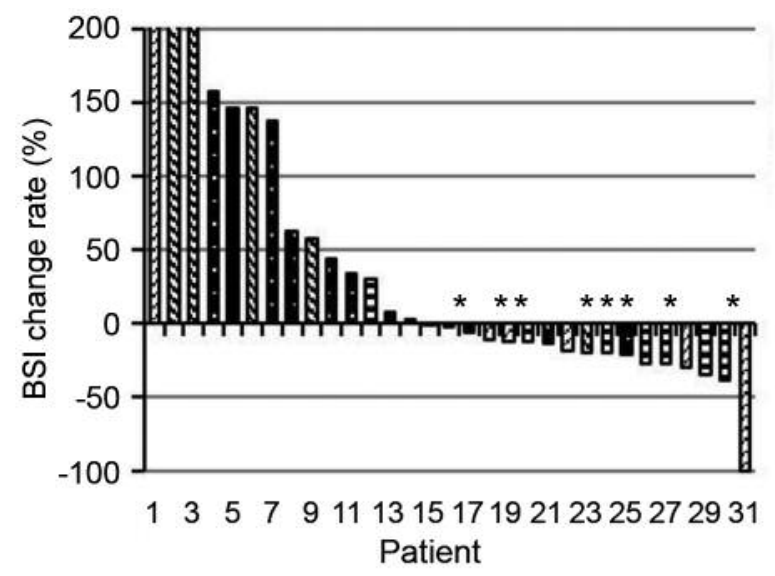

$\square$ ABI pre-DOC

ABI post-DOC

- ENZ pre-DOC

ENZ post-DOC

* Flare case

Figure 3. Waterfall plots of BSI change rate (considering flare phenomenon).

Improvement of BSI from bone scintigraphy was worse than the PSA change ratio. Flare phenomenon in bone scintigraphy was also considered; "BSI flare phenomenon" refers to cases in which BSI reductions are followed after 3 months of ENZ or ABI treatment by elevations in BSI, despite a continuous decrease in PSA. Figure 2A shows a representative case. BSI change rate was therefore calculated against the maximal BSI level after ENZ or ABI treatment, rather than treatment baseline (Figure 2B). According to this definition, 17 of 31 patients (54.8\%) demonstrated a decrease in BSI, including 12 (38.7\%) pre-DOC and $5(16.1 \%)$ postDOC (Figure 3). BSI flare phenomenon was observed in 8 of 17 patients with a decrease in BSI. Median BSI change rates for pre-DOC patients were significantly better than for post-DOC patients, with both ENZ and ABI $(-19.0 \%$ vs. $43.9 \% ; p=0.0018 *$ ).

Considering the BSI flare phenomenon, a mild correlation was observed between BSI change rate and PSA change rate $\left(y=3.182 x+205.749, R^{2}=0.499\right)$ (Figure 4). Median OS after ENZ or ABI treatment on Kaplan-Meier curves was 29.0 months (95\% confidential interval $[\mathrm{CI}]=28.1-37.2$ months) (Figure 5A). Given the median BSI value of $1.797 \%$, the cohort was divided into two groups; high BSI group (BSI $\geq 1.797 \%$, 16 patients) and low BSI group (BSI $<1.797 \%, 15$ patients). Median OS for patients with low BSI after ENZ or ABI treatment was not reached; median OS for patients with high

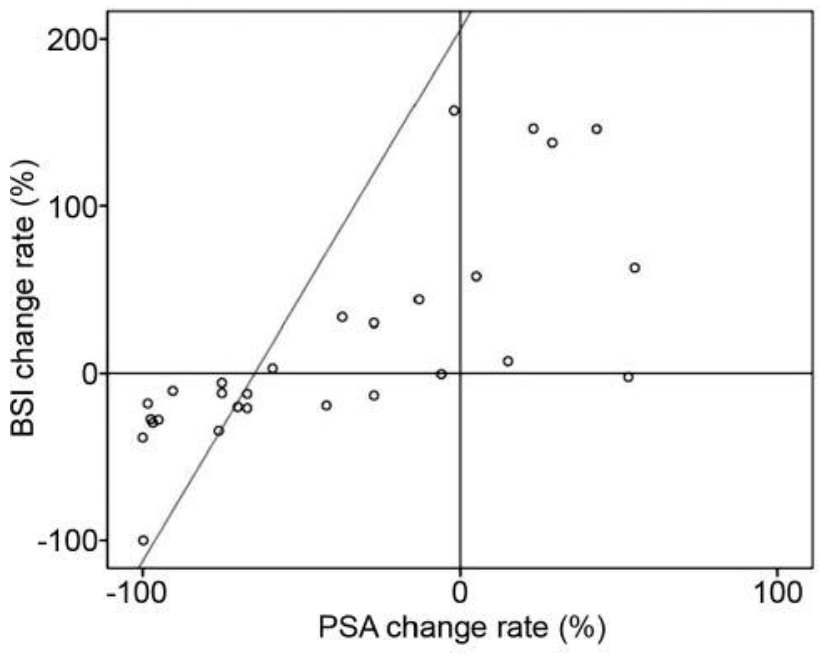

Figure 4. Correlation between BSI change rate and PSA change rate. $B S I$ change rate was significantly correlated with PSA change rate $\left(y=3.182 x+205.749, R^{2}=0.499\right)$.

BSI was 24.0 months $\left(p=0.003^{*}\right)$ (Figure 5B). Moreover, median OS for patients demonstrating a decrease in BSI through ENZ or ABI treatment was not reached; median OS for patients with elevated BSI was 15.0 months $(p=0.01 *)$ (Figure 5C).

In univariate analysis, baseline pain (yes $v s$. no; hazard ratio $[\mathrm{HR}]=4.173 ; 95 \% \mathrm{CI}=1.359-12.812 ; p=0.013 *$ ), post-DOC (yes vs. no; $\mathrm{HR}=3.404 ; 95 \% \mathrm{CI}=1.036-11.184 ; p=0.044 *)$, decreased BSI following ENZ or ABI treatment (no vs. yes; $\mathrm{HR}=5.061$; 95\%CI $=1.522-16.829 ; p=0.008 *)$, baseline BSI $(\geq 1.797 \%$ vs. $<1.797 \%$; HR=4.259; 95\%CI=0940-19.309; $p=0.048 *$ ), and decreased PSA following ENZ or ABI treatment (no vs. yes; $\mathrm{HR}=3.542 ; 95 \% \mathrm{CI}=1.130-11.106 ; p=0.030^{*}$ ) were identified as significant predictors for longer OS (Table II). In multivariate analysis, decreased BSI following ENZ or ABI treatment (no vs. yes; HR=7.025; 95\% CI=1.040-47.452; $\left.p=0.045^{*}\right)$ and baseline BSI $<1.797 \%(\geq 1.797$ vs. $<1.797$; $\mathrm{HR}=8.009 ; 95 \% \mathrm{CI}=1.160-55.320 ; p=0.035 *)$ were identified as independent predictors of longer OS (Table II).

\section{Discussion}

Many physicians use PSA when following-up PCa patients with bone metastasis. However, PSA is not a good surrogate marker, and can only be used to evaluate effectiveness of treatment $(17,18)$. Miyoshi et al. previously reported, based on multivariate analysis, that decreased PSA was not a prognostic marker for OS during ABI or ENZ treatment (19). Given that many mCRPC patients have bone metastasis, accurate assessment of bone metastasis during treatment is important to assess prognosis $(5,20)$. Although EOD score is widely used to assess bone metastasis, it lacks quantitative 

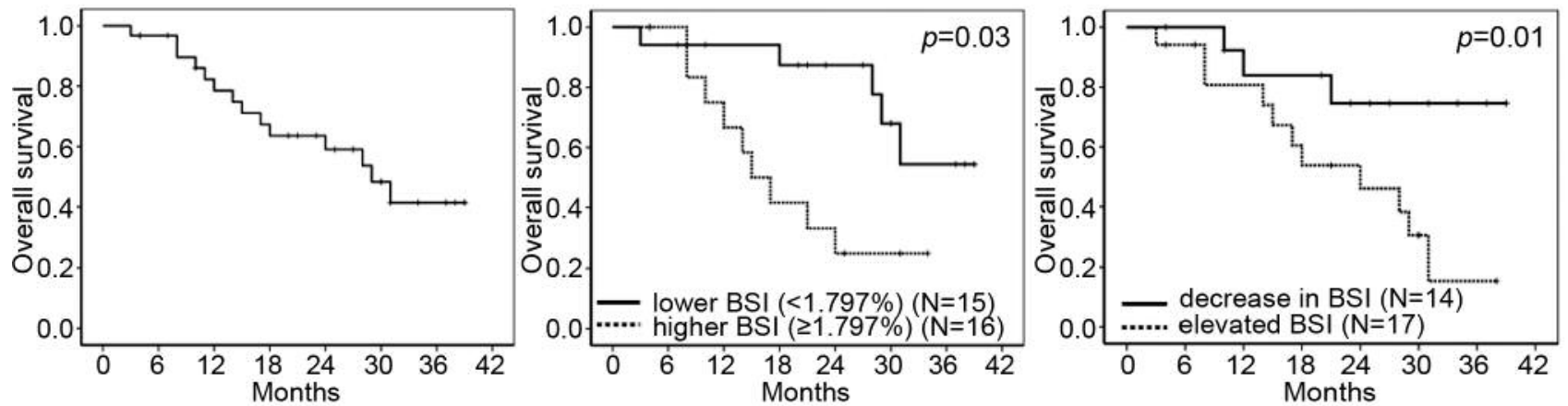

Figure 5. Kaplan-Meier curve for OS after ENZ or ABI treatment by change of BSI. A. Median OS for all patients after ENZ/ABI treatment on Kaplan-Meier curves was 29.0 months. B. Lower BSI group $(B S I<1.797)$ had significantly longer OS than the higher BSI group (BSI $\geq 1.797)$ $\left(p=0.03^{*}\right)$. C. Median OS for patients with BSI decrease following ENZ/ABI treatment was significantly longer than median OS for patients with elevated BSI $(p=0.01 *)$.

Table II. Univariate and multivariate analyses of predictors for overall survival by ENZ/ABI treatment, Cox proportional hazards models.

\begin{tabular}{|c|c|c|c|c|c|c|c|c|}
\hline & \multicolumn{2}{|c|}{ Univariate } & \multicolumn{6}{|c|}{ Multivariate } \\
\hline & \multicolumn{5}{|c|}{$95 \% \mathrm{CI}$} & \multicolumn{3}{|c|}{$95 \% \mathrm{CI}$} \\
\hline & $p$-Value & HR & Lower & Upper & $p$-Value & HR & Lower & Upper \\
\hline Age, y $(\geq 70 v s .<70)$ & 0.921 & 1.057 & 0.354 & 3.156 & & & & \\
\hline ECOG PS, $(\leq 2 v s . \geq 1)$ & 0.116 & 2.848 & 0.773 & 10.496 & & & & \\
\hline Baseline Pain (yes $v s$. no) & 0.013 & 4.173 & 1.359 & 12.812 & 0.469 & 1.655 & 0.423 & 6.467 \\
\hline GS $(\geq 9 v s . \leq 8)$ & 0.701 & 1.246 & 0.405 & 3.833 & & & & \\
\hline Post DOC (yes vs. no) & 0.044 & 3.404 & 1.036 & 11.184 & 0.349 & 1.901 & 0.548 & 7.287 \\
\hline BSI flare, (no $v s$. yes) & 0.119 & 2.907 & 0.759 & 11.131 & & & & \\
\hline BSI decline after ENZ/ ABI (no vs. yes) & 0.008 & 5.061 & 1.522 & 16.829 & 0.045 & 7.025 & 1.040 & 47.452 \\
\hline Baseline BSI, \% ( $\geq 1.797 v s .<1.797)$ & 0.048 & 4.259 & 0.940 & 19.309 & 0.035 & 8.009 & 1.160 & 55.320 \\
\hline PSA decline after ENZ/ABI (no vs. yes) & 0.030 & 3.542 & 1.130 & 11.106 & 0.680 & 1.395 & 0.286 & 6.809 \\
\hline Baseline PSA, ng/ml ( $\geq 16.5$ vs. <16.5) & 0.95 & 2.614 & 0.846 & 8.083 & & & & \\
\hline
\end{tabular}

properties (11). BSI evaluation enables quantitative evaluation of bone metastasis, unlike EOD (21). Therefore, we sought to analyze the relationship between OS after ENZ or ABI treatment and BSI, as well as patient age, ECOG PS, baseline pain, GS pre/post-DOC, decrease in PSA, baseline PSA and baseline BSI using Cox proportional hazards model.

Firstly, a decrease in PSA was observed in 22 of 31 patients (median $=-68.5 \%-2 \%$ to $-100 \%$ ), which is in keeping with findings in other studies $(6,7)$. Secondly, we evaluated the usefulness of BSI as a prognostic biomarker in bone metastatic CRPC patients, and the effect of ENZ or ABI treatment on bone metastasis. Baseline BSI in our study was a useful predictive marker for OS. Several studies have shown that baseline BSI and BSI changes in response to CRPC treatment are predictive markers of prognosis $(19,22-24)$. However, the number of patients demonstrating a decrease in BSI following treatment with AR axis targeted agents was low, compared to the number of patients with a decrease in PSA following ABI or ENZ treatment $(35-37 \%)(19,24)$. In the present study, 11 of 31 patients $(35.5 \%)$ experienced a decrease in BSI following ABI or ENZ treatment, while 22 of 31 patients $(71 \%)$ experienced a decrease in PSA.

Accumulation of bone scintigraphy lesions and PSA levels may temporarily increase during effective treatment, commonly known as the "flare phenomenon" $(13,25,26)$. 99mTc-methylene diphosphonate (MDP), used for bone scintigraphy, accumulates during bone metabolism, especially in sites of enhanced bone formation. Therefore, accumulation of bone scintigraphy in a BSI flare may represent a recovery of bone tissue due to reduction of bone metastatic lesions. We subsequently re-analyzed BSI changes considering BSI flares. As a result, $54.8 \%$ of patients experienced BSI improvements when including BSI flare. Furthermore, in multivariate analysis, BSI decrease, with 
BSI flare considered, was indicated as an independent predictor of longer OS. It is, therefore, necessary to keep in mind the possibility of the flare phenomenon when increased BSI is observed during ENZ or ABI treatment of CRPC.

Considering that the median BSI change in the present study was $-2.1 \%$ (range $=-100 \%$ to $+1930 \%$ ), effectiveness of ENZ or ABI against mCRPC was confirmed by a change in BSI. Patients treated with ENZ or ABI pre-DOC showed significant decrease in BSI. However, 18 patients had BSI measurements during DOC treatment, and reductions in BSI in these patients tended to be better than reductions in BSI following pre-DOC treatment with ENZ or ABI $(-34.0$ vs. $-19.0 \%$; $p=0.2064$ ) (data not shown). Therefore, it is necessary to evaluate the order of ENZ/ABI and DOC treatment when treating CRPC with bone metastasis.

A positive correlation was observed between PSA change and BSI change, in keeping with previous literature (13). However, in some cases, BSI continued to increase despite a decrease in PSA. Therefore, BSI on bone scintigraphy should be evaluated as well as PSA to accurately judge the situation of CRPC during various therapies.

Our research has several limitations, including the small cohort size and the retrospective design. A larger prospective clinical trial should validate the usefulness of BSI as a biomarker for CRPC with bone metastasis.

This study demonstrated that low baseline BSI before treatment and a decrease in BSI are independent predictors for longer OS. To properly treat bone metastatic CRPC, it is important to evaluate bone metastasis using BSI, paying attention to the flare phenomenon.

\section{Conflicts of Interest}

No potential conflicts of interest relevant to this article are reported.

\section{Authors' Contributions}

Conception and design: Atsushi Mizokami; Acquisition of data: Suguru Kadomoto. Analysis and interpretation of data: Suguru Kadomoto; Drafting of the manuscript: Suguru Kadomoto; Critical revision of the manuscript for important intellectual content: Atsushi Mizokami; Statistical analysis: Suguru Kadomoto; Administrative, technical or material support: Hiroshi Yaegashi, Kazufumi Nakashima, Masashi Iijima, Shohei Kawaguchi, Takahiro Nohara, Kazuyoshi Shigehara, Kouji Izumi, Yoshifumi Kadono and Kenichi Nakajima; Approval of the version of the manuscript to be published: Suguru Kadomoto, Hiroshi Yaegashi, Kazufumi Nakashima, Masashi Iijima, Shohei Kawaguchi, Takahiro Nohara, Kazuyoshi Shigehara, Kouji Izumi, Yoshifumi Kadono, Kenichi Nakajima and Atsushi Mizokami

\section{Acknowledgements}

The Authors are grateful to Mr. Brendan for carefully proofreading the manuscript.

\section{References}

1 Huggins $\mathrm{C}$ and Hodges CV: Studies on prostatic cancer. I. The effect of castration, of estrogen and of androgen injection on serum phosphatases in metastatic carcinoma of the prostate. 1941. J Urol 167: 948-951, 2002. PMID: 11905923.

2 Small EJ and Vogelzang NJ: Second-line hormonal therapy for advanced prostate cancer: a shifting paradigm. J Clin Oncol 15: 382-388, 1997. PMID: 8996165. DOI: 10.1200/JCO.1997. 15.1 .382

3 Oh WK and Kantoff PW: Management of hormone refractory prostate cancer: current standards and future prospects. J Urol 160: 1220-1229, 1998. PMID: 9751323.

4 Hori M, Matsuda T, Shibata A, Katanoda K, Sobue T and Nishimoto H: Cancer incidence and incidence rates in Japan in 2009: A study of 32 population-based cancer registries for the Monitoring of Cancer Incidence in Japan (MCIJ) project. Jpn J Clin Oncol 45: 884-891, 2015. PMID: 26142437. DOI: 10.1093/jjco/hyv088

5 Tannock IF, de Wit R, Berry WR, Horti J, Pluzanska A, Chi KN, Oudard S, Theodore C, James ND, Turesson I, Rosenthal MA and Eisenberger MA: Docetaxel plus prednisone or mitoxantrone plus prednisone for advanced prostate cancer. N Engl J Med 351: 1502-1512, 2004. PMID: 15470213. DOI: 10.1056/NEJMoa 040720

6 de Bono JS, Logothetis CJ, Molina A, Fizazi K, North S, Chu L, Chi KN, Jones RJ, Goodman OB, Jr., Saad F, Staffurth JN, Mainwaring P, Harland S, Flaig TW, Hutson TE, Cheng T, Patterson H, Hainsworth JD, Ryan CJ, Sternberg CN, Ellard SL, Flechon A, Saleh M, Scholz M, Efstathiou E, Zivi A, Bianchini D, Loriot Y, Chieffo N, Kheoh T, Haqq CM and Scher HI: Abiraterone and increased survival in metastatic prostate cancer. N Engl J Med 364: 1995-2005, 2011. PMID: 21612468. DOI: 10.1056/NEJMoa1014618

7 Scher HI, Fizazi K, Saad F, Taplin ME, Sternberg CN, Miller K, de Wit R, Mulders P, Chi KN, Shore ND, Armstrong AJ, Flaig TW, Flechon A, Mainwaring P, Fleming M, Hainsworth JD, Hirmand M, Selby B, Seely L and de Bono JS: Increased survival with enzalutamide in prostate cancer after chemotherapy. N Engl J Med 367: 1187-1197, 2012. PMID: 22894553. DOI: 10.1056/NEJMoa1207506

8 Ryan CJ, Smith MR, de Bono JS, Molina A, Logothetis CJ, de Souza P, Fizazi K, Mainwaring P, Piulats JM, Ng S, Carles J, Mulders PF, Basch E, Small EJ, Saad F, Schrijvers D, Van Poppel H, Mukherjee SD, Suttmann H, Gerritsen WR, Flaig TW, George DJ, Yu EY, Efstathiou E, Pantuck A, Winquist E, Higano CS, Taplin ME, Park Y, Kheoh T, Griffin T, Scher HI and Rathkopf DE: Abiraterone in metastatic prostate cancer without previous chemotherapy. N Engl J Med 368: 138-148, 2013. PMID: 23228172. DOI: 10.1056/NEJMoa1209096

9 Beer TM, Armstrong AJ, Rathkopf DE, Loriot Y, Sternberg CN, Higano CS, Iversen P, Bhattacharya S, Carles J, Chowdhury S, Davis ID, de Bono JS, Evans CP, Fizazi K, Joshua AM, Kim CS, Kimura G, Mainwaring P, Mansbach H, Miller K, Noonberg SB, Perabo F, Phung D, Saad F, Scher HI, Taplin ME, Venner PM and Tombal B: Enzalutamide in metastatic prostate cancer before chemotherapy. N Engl J Med 371: 424-433, 2014. PMID: 24881730. DOI: 10.1056/NEJMoa1405095

10 Scher HI, Halabi S, Tannock I, Morris M, Sternberg CN, Carducci MA, Eisenberger MA, Higano C, Bubley GJ, Dreicer R, Petrylak 
D, Kantoff P, Basch E, Kelly WK, Figg WD, Small EJ, Beer TM, Wilding G, Martin A and Hussain M: Design and end points of clinical trials for patients with progressive prostate cancer and castrate levels of testosterone: recommendations of the Prostate Cancer Clinical Trials Working Group. J Clin Oncol 26: 11481159, 2008. PMID: 18309951. DOI: 10.1200/jco.2007. 12.4487

11 Soloway MS, Hardeman SW, Hickey D, Raymond J, Todd B, Soloway S and Moinuddin M: Stratification of patients with metastatic prostate cancer based on extent of disease on initial bone scan. Cancer 61: 195-202, 1988. PMID: 3334948.

12 Armstrong AJ: Docetaxel for advanced prostate cancer: How early to start? Lancet Oncol 16: 741-742, 2015. PMID: 26028517. DOI: $10.1016 / \mathrm{s} 1470-2045(15) 00012-1$

13 Scher HI, Morris MJ, Stadler WM, Higano C, Basch E, Fizazi K, Antonarakis ES, Beer TM, Carducci MA, Chi KN, Corn PG, de Bono JS, Dreicer R, George DJ, Heath EI, Hussain M, Kelly WK, Liu G, Logothetis C, Nanus D, Stein MN, Rathkopf DE, Slovin SF, Ryan CJ, Sartor O, Small EJ, Smith MR, Sternberg CN, Taplin ME, Wilding G, Nelson PS, Schwartz LH, Halabi S, Kantoff PW and Armstrong AJ: Trial design and objectives for castration-resistant prostate cancer: Updated Recommendations From the Prostate Cancer Clinical Trials Working Group 3. J Clin Oncol 34: 1402-1418, 2016. PMID: 26903579. DOI: 10.1200/jco.2015.64.2702

14 Erdi YE, Humm JL, Imbriaco M, Yeung H and Larson SM: Quantitative bone metastases analysis based on image segmentation. J Nucl Med 38: 1401-1406, 1997. PMID: 9293797.

15 Ulmert D, Kaboteh R, Fox JJ, Savage C, Evans MJ, Lilja H, Abrahamsson PA, Bjork T, Gerdtsson A, Bjartell A, Gjertsson P, Hoglund P, Lomsky M, Ohlsson M, Richter J, Sadik M, Morris MJ, Scher HI, Sjostrand K, Yu A, Suurkula M, Edenbrandt L and Larson SM: A novel automated platform for quantifying the extent of skeletal tumour involvement in prostate cancer patients using the Bone Scan Index. Eur Urol 62: 78-84, 2012. PMID: 22306323. DOI: 10.1016/j.eururo.2012.01.037

16 Koizumi M, Wagatsuma K, Miyaji N, Murata T, Miwa K, Takiguchi T, Makino $\mathrm{T}$ and Koyama M: Evaluation of a computer-assisted diagnosis system, BONENAVI version 2, for bone scintigraphy in cancer patients in a routine clinical setting. Ann Nucl Med 29: 138-148, 2015. PMID: 25326907. DOI: 10.1007/s12149-014-0921-y

17 Scher HI, Morris MJ, Basch E and Heller G: End points and outcomes in castration-resistant prostate cancer: from clinical trials to clinical practice. J Clin Oncol 29: 3695-3704, 2011. PMID: 21859988. DOI: 10.1200/jco.2011.35.8648

18 Izumi K, Lin WJ, Miyamoto H, Huang CK, Maolake A, Kitagawa Y, Kadono Y, Konaka H, Mizokami A and Namiki M: Outcomes and predictive factors of prostate cancer patients with extremely high prostate-specific antigen level. J Cancer Res Clin Oncol 140: 1413-1419, 2014. PMID: 24747988. DOI: 10.1007/ s00432-014-1681-8

19 Miyoshi Y, Uemura K, Kawahara T, Yoneyama S, Hattori Y, Teranishi JI, Ohta JI, Takebayashi S, Yokomizo Y, Hayashi N, Yao $\mathrm{M}$ and Uemura $\mathrm{H}$ : Prognostic value of automated bone scan index in men with metastatic castration-resistant prostate cancer treated with enzalutamide or abiraterone acetate. Clin Genitourin Cancer 15: 472-478, 2017. PMID: 28110835. DOI: 10.1016/ j.clgc.2016.12.020
20 Petrylak DP, Ankerst DP, Jiang CS, Tangen CM, Hussain MH, Lara PN, Jr., Jones JA, Taplin ME, Burch PA, Kohli M, Benson MC, Small EJ, Raghavan D and Crawford ED: Evaluation of prostate-specific antigen declines for surrogacy in patients treated on SWOG 99-16. J Natl Cancer Inst 98: 516-521, 2006. PMID: 16622120. DOI: 10.1093/jnci/djj129

21 Wakabayashi H, Nakajima K, Mizokami A, Namiki M, Inaki A, Taki $\mathbf{J}$ and Kinuya S: Bone scintigraphy as a new imaging biomarker: the relationship between bone scan index and bone metabolic markers in prostate cancer patients with bone metastases. Ann Nucl Med 27: 802-807, 2013. PMID: 23828554. DOI: $10.1007 / \mathrm{s} 12149-013-0749-\mathrm{x}$

22 Anand A, Morris MJ, Larson SM, Minarik D, Josefsson A, Helgstrand JT, Oturai PS, Edenbrandt L, Roder MA and Bjartell A: Automated Bone Scan Index as a quantitative imaging biomarker in metastatic castration-resistant prostate cancer patients being treated with enzalutamide. EJNMMI Res 6: 23, 2016. PMID: 26960325. DOI: 10.1186/s13550-016-0173-Z

23 Mitsui Y, Shiina H, Yamamoto Y, Haramoto M, Arichi N, Yasumoto H, Kitagaki $\mathrm{H}$ and Igawa M: Prediction of survival benefit using an automated bone scan index in patients with castration-resistant prostate cancer. BJU Int 110: E628-634, 2012. PMID: 22788759. DOI: 10.1111/j.1464-410X.2012. 11355.x

24 Reza M, Jones R, Aspegren J, Massard C, Mattila L, Mustonen M, Wollmer P, Tragardh E, Bondesson E, Edenbrandt L, Fizazi $\mathrm{K}$ and Bjartell $\mathrm{A}$ : Bone Scan Index and progression-free survival data for progressive metastatic castration-resistant prostate cancer patients who received ODM-201 in the ARADES multicentre study. Eur Urol Focus 2: 547-552, 2016. PMID: 28723521. DOI: 10.1016/j.euf.2016.01.005

25 Cook GJ, Venkitaraman R, Sohaib AS, Lewington VJ, Chua SC, Huddart RA, Parker CC, Dearnaley DD and Horwich A: The diagnostic utility of the flare phenomenon on bone scintigraphy in staging prostate cancer. Eur J Nucl Med Mol Imaging 38: 713, 2011. PMID: 20697891. DOI: 10.1007/s00259-010-1576-0

26 Morris MJ, Molina A, Small EJ, de Bono JS, Logothetis CJ, Fizazi K, de Souza P, Kantoff PW, Higano CS, Li J, Kheoh T, Larson SM, Matheny SL, Naini V, Burzykowski T, Griffin TW, Scher HI and Ryan CJ: Radiographic progression-free survival as a response biomarker in metastatic castration-resistant prostate cancer: COU-AA-302 results. J Clin Oncol 33: 13561363, 2015. PMID: 25624432. DOI: 10.1200/jco.2014.55.3875

Received March 14, 2019

Revised March 28, 2019

Accepted April 1, 2019 